
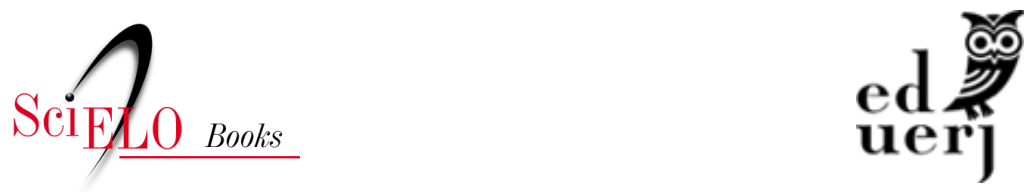

Parte II - Princípios teóricos e práticos para o cotidiano escolar de crianças, jovens e adultos em Roda de Conversas

\title{
Capítulo 7 - Relações entre a Saúde e a Educação: as ciências da visão a favor da escola
}

\author{
Viviam Kazue Andó Vianna Secin
}

\section{SciELO Books / SciELO Livros / SciELO Libros}

SECIN, V.K.A.V. Relações entre a Saúde e a Educação: as ciências da visão a favor da escola. In: FERNANDES, A.P., and LOPES, P.C., eds. $O$ cotidiano escolar de crianças, jovens e adultos em rodas de conversas [online]. Rio de Janeiro: EDUERJ, 2020, pp. 153-168. ISBN: 978-6587949-02-4. https://doi.org/10.7476/9786587949024.0009.

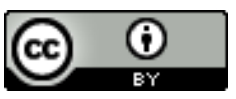

All the contents of this work, except where otherwise noted, is licensed under a Creative Commons Attribution 4.0 International license.

Todo o conteúdo deste trabalho, exceto quando houver ressalva, é publicado sob a licença Creative Commons Atribição 4.0.

Todo el contenido de esta obra, excepto donde se indique lo contrario, está bajo licencia de la licencia Creative Commons Reconocimento 4.0. 


\section{Capítulo 7 \\ Relaçóes entre a Saúde e a Educação: as ciências da visão a favor da escola}

Viviam Kazue Andó Vianna Secin

\section{Introdução}

Este capítulo apresenta um convite à aproximação dos diferentes atores envolvidos no desafio multidimensional e interdisciplinar inerente ao processo de letramento vivenciado cotidianamente por crianças, jovens e adultos em nosso país.

Como profissional da área de saúde visual Ortóptica ${ }^{1}$ e membro do Grupo de Pesquisas Linguagem, Cognição Humana e Processos Educacionais, do Programa de Pós-Graduação em Educação da Universidade do Estado do Rio de Janeiro, liderado pelo linguista professor doutor Luiz Antônio Gomes Senna, tenho procurado empreender movimentos interdisciplinares inerentes aos objetivos do grupo de pesquisa, em favor da caracterização do conceito de letramento e do reconhecimento do sujeito do letramento

1 Ortóptica é a ciência cujo objeto de estudo é a visão binocular, em seus aspectos sensoriais e motores, e sua influência para o desenvolvimento global do ser humano (Secin, 2011). O ortoptista é o profissional que atua em complementariedade ao médico oftalmologista, na habilitação e reabilitação de pacientes com alteraçôes da visão binocular por dificuldades de controle estático e dinâmico dos olhos, como na insuficiência de convergência e nos estrabismos. 
pertencente ao contexto escolar brasileiro, pela aproximação entre as áreas das ciências da visão e da Educação Inclusiva. ${ }^{2}$

O conceito de letramento a que se refere este capítulo é entendido como um processo de desenvolvimento global do indivíduo, tornando-o capaz de transitar e operar, nos diferentes espaços do gradiente cultural, sem perder sua identidade plural. Em sua dimensão ética, deve possibilitar o desenvolvimento do cidadão e o reconhecimento de seus valores culturais, para que seja capaz de reconhecer e dialogar com o outro, interagir e transitar tanto nos domínios da oralidade quanto da cientificidade (Senna, 2007).

O letramento é considerado para além das atividades de ler e escrever, contemplando novos aspectos da oralidade, da psicomotricidade, da cognição e da visualidade e favorecendo o transitar entre uma psicomotricidade científica e uma psicomotricidade narrativa. Ressalta Senna a necessidade de se reconhecer a existência de diferentes sujeitos mediadores desse processo, sejam eles agentes formais ou informais da educação, assim como eu, profissional de saúde da visão.

Educação, saúde e cultura como direitos universais humanos, assim como o respeito às diferenças humanas, são reconhecidos desde 1948 pela Declaração Universal dos Direitos Humanos. Mas "Educação para Todos", como consenso mundial, deu-se em 1990, quando foi proposta a universalização do acesso à educação básica com equidade e respeito à diversidade humana e a superação de entraves à participação ativa no processo educativo, como o preconceito e os estereótipos aplicados aos grupos sociais marginalizados, tais como os pobres, as minorias (étnicas, raciais e linguísticas) e os refugiados de guerras (ONU, Declaração de Jontien, 1990).

O entrelaçamento entre os conceitos de educação, saúde e cultura foi objeto de discussóes promovidas pela Organização

2 Grupo de Pesquisas Linguagem, Cognição Humana e Processos Educacionais. Disponível em: www.senna.pro.br. 
Mundial de Saúde (OMS) e pelo Fundo das Naçôes Unidas para a Infância (UNICEF), desde a Declaraçáo de Alma-Ata, no Cazaquistão, em 1978, que abriu caminho para a instituição de um novo paradigma em saúde mundial, baseado na estratégia de atenção primária em destaque desde a Primeira Conferência Internacional sobre Promoção da Saúde, a promulgação da Carta de Ottawa, no Canadá, em 1986, e, posteriormente, pela proposta de "Saúde Para Todos", no ano 2000. Desde então, o contexto social e os fatores ambientais passaram a ser considerados importantes determinantes da saúde (Brasil/MS, 2002; Mendes, 2004; OMS, 2013).

Esse importante marco mundial ressaltou a importância do comprometimento interdisciplinar e intersetorial e apresentou o conceito de promoção da saúde como sendo o processo de capacitaçáo da comunidade para atuar na melhoria de sua qualidade de vida e saúde, assim como na modificação favorável do meio ambiente. A partir dela, a saúde passou a ser um recurso para a vida e não o objetivo de viver (OPAS, 2010).

No Brasil, a Lei n. ${ }^{\circ}$ 8.080/90 estabeleceu ser a saúde uma responsabilidade do Estado compartilhada com os diferentes setores da sociedade, ressaltando como determinantes e condicionantes da saúde a educação, a alimentação, a moradia, o saneamento básico, o meio ambiente, o trabalho, a renda, o transporte, o lazer e o acesso aos bens e serviços (Brasil, 1990).

Em uma perspectiva ecológica de saúde, atrelada aos modos de vida e dotada de um caráter sistêmico e interdisciplinar, passou-se a considerar o sujeito em sua complexa interação com diversas dimensóes (biológicas, psicossociais, ambientais, culturais, econômicas, históricas etc.).

Em termos da saúde da visão, para além dos aspectos específicos oculares, tornou-se imprescindível entendê-la como parte de um vasto sistema de relaçóes que afetam a saúde global e a qualidade de vida dos diferentes sujeitos, estando atrelada às práticas sociais cotidianas, educacionais, culturais, de lazer, profissionais etc. 
Considerando a importância da visão para o processo de desenvolvimento global do ser humano e, em especial, para os processos de alfabetização e inclusão social, vale mencionar dados levantados a partir de estudos populacionais realizados entre os anos de $1980 \mathrm{e}$ 2015, que alertam para a necessidade de se sensibilizar a todos em favor de milhóes de pessoas que hoje sofrem impactos negativos em suas vidas devido a problemas visuais (Bourne et al., 2017).

Considerando a população aproximada de 7,33 bilhóes de pessoas no mundo no ano de 2015, estimou-se a existência de, aproximadamente, 253 milhóes de pessoas com algum tipo de deficiência visual, das quais 36 milhóes de pessoas seriam cegas. E, ainda, advertia-se para a oportunidade de se promover uma mudança na vida dessas milhôes de pessoas, uma vez que $80 \%$ dessas causas seriam evitáveis ou curáveis a partir do acesso a cuidados em saúde da visão efetivos nos diferentes países (Bourne et al., 2017; IAPB, 2019; OMS, 2013).

Saúde como um direito de todos é parte do texto constitucional brasileiro do ano de 1988 (Brasil, 1988). No entanto, o direito à saúde ocular no Brasil é uma conquista mais recente. Seguindo recomendaçôes internacionais para a democratização da atenção em saúde da visão (OMS, UNESCO e Associação Internacional de Prevenção da Cegueira/IAPB) e visando a atender a meta mundial do Programa 2020, da OMS, para redução da cegueira evitável no mundo até o ano de 2020, instituiu-se, no ano de 2008, a Política Nacional de Atenção em Oftalmologia, que garantiu o acesso universal aos serviços de saúde visual a todos os brasileiros (Brasil/ MS, 2008; IAPB, 2019).

Mais recente ainda é a Lei Brasileira de Inclusão da Pessoa com Deficiência (Lei n.o 13.146/15), instituída no ano de 2015, de modo a assegurar e a promover, em condiçóes de igualdade, $\mathrm{o}$ exercício dos direitos e das liberdades fundamentais da pessoa com deficiência, visando à sua inclusão social e à cidadania (Brasil, 2015). 
Essa lei estabelece, em seu artigo $2 .^{\circ}$, que a pessoa com deficiência é aquela que tem impedimentos de longo prazo de natureza física, mental, intelectual ou sensorial, os quais, em interação com uma ou mais barreiras, podem obstruir sua participação plena e efetiva na sociedade em igualdade de condiçóes com as demais pessoas. E, ainda, ressalta que a avaliação da deficiência deve ser biopsicossocial e realizada por equipe multiprofissional e interdisciplinar, considerando aspectos como impedimentos nas funçôes e nas estruturas do corpo, fatores socioambientais, psicológicos e pessoais, a limitação no desempenho de atividades e a restrição de participação.

Em termos de Saúde, no artigo 18 da referida Lei, é assegurada atenção integral à saúde da pessoa com deficiência em todos os níveis de complexidade, por intermédio do Sistema Único de Saúde, garantindo acesso universal e igualitário também à atenção em saúde visual.

Em termos do direito à Educação, o artigo 27 estabelece o direito à educação em sistema educacional inclusivo em todos os níveis e aprendizado ao longo de toda a vida, de forma a alcançar o máximo desenvolvimento possível de seus talentos e habilidades físicas, sensoriais, intelectuais e sociais, segundo suas características, interesses e necessidades de aprendizagem. Nesse aspecto, contempla-se também o acesso à educação aos deficientes visuais e também daqueles que apresentam diferenças funcionais binoculares instituídas em diferentes rotas ecológicas de desenvolvimento binocular, próprias à diversidade cultural e aos diferentes usos cotidianos dos olhos. Essa diversidade visual ecologicamente instituída demanda especial atenção dos educadores, pois nem sempre leva ao desenvolvimento de habilidades binoculares necessárias ao uso dos olhos no processo de aprendizagem da leitura.

O processo de inclusão do deficiente visual já se faz presente em nossos marcos legais. No entanto, o reconhecimento da existência de uma ecologia do olhar e uma diversidade visual inerente aos diferentes estilos de vida e aos usos cotidianos dos olhos próprios 
a cada cultura ainda merece a atenção daqueles que se dedicam ao campo da Educação Inclusiva, sendo essa visão ecológica e seus impactos para o processo de letramento o objeto de reflexão deste texto, que tem por objetivo apresentar ao leitor aspectos binoculares importantes a serem considerados por aqueles que lidam cotidianamente com os alunos culturalmente diversos das escolas brasileiras e que podem representar dificuldades adicionais ao já complexo processo de alfabetização e letramento.

O diálogo interdisciplinar aqui proposto exige um esforço adicional do leitor para que possa lidar com novos conceitos inerentes ao percurso reflexivo que se dirige a territórios além das fronteiras de nossos campos profissionais, importante exercício e inerente àqueles que se propóem a buscar a aproximação entre os diferentes saberes.

\section{Visão, desenvolvimento e o letramento}

A visão é um sentido humano fundamental desde o nascimento. Por meio da visão, iniciamos nossos primeiros contatos com o mundo ao redor e com o(s) outro(s), seja na relação mãe e filho, seja em família ou com os demais membros da comunidade. $\mathrm{O}$ sistema visual está presente, ainda que de modo incipiente, desde os primeiros momentos de vida, sendo o bebê capaz de perceber objetos próximos e de altos contrastes e reconhecer rostos familiares.

A adequada experiência visual da criança permitirá amadurecer suas estruturas visuais e alcançar a visão discriminativa do adulto, havendo um período de desenvolvimento que se inicia ao nascimento e se torna pleno ao redor dos 6 a 7 anos de idade. Trata-se de uma importante janela de tempo para o desenvolvimento da visão, quando atitudes preventivas, a detecção precoce de agravos visuais e a intervenção oportuna favorecem o melhor prognóstico.

O sentido da visão nos permite não somente a apreensão do mundo exterior, sendo fundamental para o entrelaçamento das 
informaçóes provenientes dos demais sistemas orgânicos. Os objetos visuais do ambiente são primariamente detectados, localizados, definidos em termos de suas formas, tamanhos, contrastes e cores. Em seguida, esses dados visuais estabelecem diferentes interconexóes no sistema nervoso, em favor do seu reconhecimento em termos conceituais, da associação com fatos da vida e emoçôes, da retenção em nossa memória, possibilitando-nos não somente o uso dessas informaçóes na linguagem, mas também no planejamento e execução de açóes corporais globais, no ajuste postural, no controle dos ritmos biológicos hormonais regulados circadianamente em termos dos ciclos dia/noite e no controle da motricidade global e fina.

Segundo o Conselho Brasileiro de Oftalmologia (Taleb et al., 2010), são diferentes as causas de problemas visuais no Brasil (catarata, glaucoma, retinopatia diabética etc.), sendo as mais frequentes entre as crianças brasileiras os problemas refracionais não corrigidos (miopia, hipermetropia e astigmatismo), que afetam o rendimento escolar e a sociabilizaçáo da criança e representam grande impacto econômico e social.

Outra causa de problemas visuais são os estrabismos, desvios do alinhamento dos olhos que afetam $2 \%$ a $4 \%$ da população infantil no mundo, com consequências motoras e sensoriais que variam em razão de sua tipologia, do momento do seu surgimento, de sua detecção precoce e do tipo de intervenção terapêutica.

Se o estrabismo ocorre ao nascimento ou nos primeiros anos de vida da criança, pode ocasionar adaptaçóes sensoriais, entre as quais, a ambliopia. ${ }^{3} \mathrm{~A}$ ambliopia pode ocorrer também em outras situaçóes de privação sensorial, como a existência de

3 Ambliopia é o termo de origem grega (amblýs: obtuso; óps: olho) que significa uma baixa visual (afetando a sensibilidade ao contraste e a localizaçáo espacial) em um olho, sem alteração ocular que a justifique, com prevalência variável na população em geral e entre $2 \%$ a $2,5 \%$ na população americana. Sua patogenia pode ser a privação sensorial pós-natal infantil, causas refracionais e o estrabismo (Souza-Dias e Goldchmit, 2011, p. 88; Von Noorden e Campos, 2002, p. 246). 
anisometropias, ${ }^{4}$ de altas ametropias ${ }^{5}$ não corrigidas ou mesmo por oclusão prolongada de um dos olhos, por diferentes razóes, até mesmo pelo uso prolongado de curativos oculares em crianças pequenas. ${ }^{6}$

Se o estrabismo é mais tardio e surge após o desenvolvimento da visão binocular, levará o indivíduo a perceber a diplopia, ${ }^{7}$ visão dupla que se torna um grande incômodo visual, que persistirá até que a alteração oculomotora seja compensada por terapia ortóptica e/ou intervençôes oftalmológicas, associadas ou não à compensação com lentes prismáticas e/ou cirurgia do desvio ocular.

Os problemas visuais, como os vícios refracionais e os estrabismos, também se associam a perturbações do desenvolvimento

4 Anisometropia é a diferença significativa refracional entre os dois olhos, que, se não compensada adequadamente com o uso de óculos ou lentes de contato na infância, pode produzir um desequilíbrio sensorial que pode levar a processos inibitórios sensoriais no olho de pior visão ou mais amétrope, com consequente supressão sensorial e ambliopização desse olho (Souza-Dias e Goldchmit, 2011, p. 91; Von Noorden e Campos, 2002, p. 250).

5 Altas Ametropias são valores refracionais elevados em ambos os olhos, especialmente nas hipermetropias, que, se não compensados com o uso de óculos ou lentes de contato na infância, podem produzir impactos negativos ao desenvolvimento visual por privação sensorial nos dois olhos e consequente ambliopia nos dois olhos (Souza-Dias e Goldchmit, 2011, p. 90).

6 Os curativos oculares que, durante o período de desenvolvimento inicial da visão, privam por período prolongado um dos olhos da criança da adequada estimulação sensorial, podem levar à ambliopização desse olho. A privação sensorial também pode se dever a casos como a catarata congênita, anomalias palpebrais, entre outras patologias que dificultem ou impeçam a formação de imagem perfeita na retina (Souza-Dias e Goldchmit, 2011, p. 91; Von Noorden e Campos, 2002, p. 252).

7 Ao surgimento de um estrabismo, o indivíduo se defronta com dois incômodos fenômenos sensoriais: a visão dupla ou diplopia e a confusão sensorial de imagens. A diplopia se deve à percepçáo de um objeto em dois diferentes lugares do espaço e a confusão em perceber dois objetos distintos em um mesmo lugar do espaço. Em estrabismos congênitos e infantis, a diplopia e a confusão são fenômenos efêmeros, ocorrendo, em seguida, adaptaçóes sensoriais de defesa, como a supressão e a correspondência sensorial retiniana anômala (Souza-Dias e Goldchmit, 2011, p. 81). No adulto, essa adaptação sensorial não ocorre, persistindo a diplopia e a confusão até que o desalinhamento dos olhos seja compensado por meio de intervenção terapêutica ortóptica, compensação do desvio com lentes prismáticas e/ou compensação cirúrgica. 
do sistema postural. Segundo o médico ortopedista e posturólogo francês Bernard Bricot, o sistema postural é influenciado por três principais captores sensoriais: podal, ocular e manducatório (ou mastigatório). Para ele, o sistema visual é o segundo mais importante captor sensorial postural, sendo suas diferentes perturbaçóes relacionadas ao surgimento de adaptaçóes posturais estudadas multidisciplinarmente pela área da Posturologia (Bricot, 2001; Secin et al., 2004).

Os distúrbios da visão binocular, entre eles, os estrabismos, são objeto de atenção da área da saúde visual, Ortóptica, e os profissionais ortoptistas atuam na habilitação e reabilitação visual. Buscam os serviços de Ortóptica pacientes com diferentes perfis de distúrbios da visão binocular e estrabismos, sejam crianças, jovens ou adultos.

Em uma perspectiva reabilitadora, a atuação se dirige ao diagnóstico do tipo de distúrbio binocular, suas consequências sensoriais e motoras e os impactos nas açóes cotidianas visuais do paciente, seja nos processos iniciais de alfabetização, seja no processo educacional mais amplo, que demanda uma leitura proveitosa e confortável, seja nos cotidianos profissional, esportivo, artístico ou demais açóes visuais que exigem uma visão discriminativa efetiva. A partir dessas informaçóes, empreendem estratégias terapêuticas específicas para buscar a melhoria das funçôes binoculares e alcançar um adequado desempenho visual.

Em uma abordagem biopsicossocial da intervenção ortóptica, baseada na concepção mais ampla de saúde e atrelada a fatores sociais e culturais, torna-se fundamental a atuação conjunta pela interdisciplinaridade e a intersetorialidade, incorporando um novo sentido social e inclusivo (Secin, 2005, 2007, 2011 e 2016).

Nessa perspectiva inclusiva de atuação, o ortoptista busca compreender a diversidade biológica e cultural de seus pacientes, entendendo-os como sujeitos únicos, idiossincráticos, dotados de uma funcionalidade binocular não necessariamente universal, pois 
se institui em diferentes percursos e contextos de vida, sendo próprios aos distintos grupos sociais e culturas. Assim, a intervenção do ortoptista deverá respeitar a diversidade biológica e cultural dos diferentes sujeitos em sua prática profissional.

\section{Diversidade visual e os impactos para o processo de letramento}

Ao longo de minha prática profissional na área de Ortóptica, com atuação no diagnóstico e terapia de transtornos sensoriais e motores da visão binocular, algumas situaçóes clínicas me chamavam a atenção, pois sinalizavam a possibilidade de existirem singularidades em termos do controle da motricidade ocular e que representariam diversidades visuais próprias ao uso dos olhos em diferentes contextos de vida, revelando diferenças funcionais até então rotuladas como inadequaçóes, distúrbios ou mesmo deficiências.

Relatos de pacientes apontavam impactos negativos ao tentarem mudar seus hábitos visuais em suas práticas profissionais, traduzidos por queixas astenópicas ${ }^{8}$ que revelavam uma dificuldade do sistema binocular em se adaptar à nova demanda oculomotora. Ou seja, a experiência visual de cada um deles, em seus contextos de origem, tornavam-nos hábeis para suas atividades pregressas, mas inábeis para as novas demandas visuais em novos contextos sociais, culturais ou profissionais.

Eram relatadas queixas visuais e a sensação de inadequação binocular tanto em casos de pacientes que informavam a transição

8 Astenopia é o nome que se dá ao conjunto de sintomas que revelam fadiga binocular consequente ao esforço dos olhos em atividades visuais discriminativas, como a leitura, e que impactam negativamente no desempenho e sinalizam uma inadequaçáo do sistema oculomotor para a execução de tais atividades, tornando-as menos produtivas. Os sintomas astenópicos mais frequentes são: cansaço visual, sonolência à leitura, embaralhamento, pular linhas ou se perder no texto, embaçamento transitório e visão dupla, ter que reler várias vezes o texto para apreender o conteúdo do texto e perda do prazer em ler (Secin, 2011; Von Noorden e Campos, 2002, p. 153). 
de seus hábitos visuais no sentido oral-letrado quanto em sentido inverso, letrado-oral.

No sentido oral-letrado, muito frequente na clínica ortóptica, crianças, jovens ou adultos oriundos de comunidades predominantemente marcadas por práticas culturais orais relatavam dificuldades no desempenho da leitura, com queixas de cansaço visual, dificuldade em se manter na linha do texto, pular linhas, embaralhar letras do texto, embaçamento transitório, visão dupla, sonolência, dores de cabeça, levando-os a um esforço demasiado, à dificuldade de apreensão do conteúdo lido e à perda do gosto pela atividade.

Os sintomas se devem ao fato de a leitura exigir náo somente uma boa acuidade visual (corrigida ou não por óculos), mas também especialmente, um controle dinâmico e fino binocular, para a adequada realização dos movimentos binoculares de varredura do texto.

Para uma boa e confortável leitura, os olhos devem realizar saltos rápidos, sendo curtos ao longo da linha do texto e longos ao final de uma linha e ao buscar a próxima linha, com períodos breves de alguns milissegundos para a sustentação do olhar e apreensão das palavras. É necessária a atuação orquestrada de um total de 18 músculos, sendo 6 extrínsecos e 3 intrínsecos em cada olho, para garantir adequada convergência assimétrica e dinâmica dos eixos visuais e alcançar visão binocular de qualidade, confortável, única e nítida, necessária à compreensão do conteúdo lido (Secin, 2011).

Uma criança, um jovem ou um adulto, que não tenha desenvolvido adequadamente tais habilidades binoculares, terá dificuldade em aprender a ler textos, poderá se queixar de sintomas desagradáveis ao esforço visual e dificilmente terá prazer pela leitura, com impactos negativos em seu percurso escolar e/ou educacional.

É importante ressaltar que tais dificuldades apresentadas pelos pacientes no consultório não se deviam a problemas de acuidade visual, não sendo corrigíveis com óculos, mas a uma dificuldade de adaptaçáo funcional do sistema binocular diante de novas demandas escolares ou profissionais. Nesses casos, a intervenção 
ortóptica os ajudava a desenvolver tais habilidades binoculares em busca de uma leitura confortável e prazerosa.

No sentido letrado-oral, menos frequente na clínica, a dificuldade visual também era relatada, em especial por profissionais letrados que passavam a viver em comunidades predominantemente marcadas pela oralidade. Como exemplo, os casos envolvendo pesquisadores médicos, antropólogos, entre outros, que, ao se mudarem para aldeias indígenas e passarem a lidar com um ambiente de floresta, sentiam-se especialmente impactados pela dificuldade em perceber os sinais de ameaça no ambiente ou de se guiar à noite pelos espaços da aldeia. Consideravam-se visualmente incompetentes para lidar com o novo ambiente, ou seja, não possuíam a mesma habilidade binocular daqueles com quem passaram a conviver, os indígenas (Secin, 2016).

\section{As ciências da visão a favor da escola}

Considerando a tradição biomédica fundamentada em parâmetros universais de normalidade, a inadequação visual da transição oralidade-escrita foi por muito tempo considerada uma incapacidade binocular, um distúrbio, pelo fato de os sujeitos não atenderem à condição funcional binocular própria ao uso dos olhos nas açôes visuais discriminativas inerentes à sociedade letrada. Essa interpretação etnocêntrica ganhava ainda maior peso se os sujeitos envolvidos pertencessem a grupos sociais marginalizados, sendo mais um fator de exclusão.

Equivocadamente considerado universal e único, o olhar disciplinado e discriminativo da cultura letrada é aprendido e se desenvolve, desde a pequena infância, pela experiência visual em ambientes que favoreçam as práticas letradas, sendo as crianças, desde cedo, estimuladas a atitudes psicomotoras e visuais próprias ao desenvolvimento de um olhar educado da escola, pelo contato com livros infantis e jogos educativos em computadores, tablets e 
smartphones. Nestes, o objetivo é a preparação sensorial e motora binocular para o olhar proximal, centrado, convergente e discriminativo necessário à leitura.

Vale ressaltar que, atualmente, o uso excessivo do olhar proximal por crianças e jovens que passam longos períodos em atividades visuais discriminativas em tablets e smartphones já se mostra prejudicial, sendo cada dia mais frequentes na clínica ortóptica as descompensaçóes binoculares por excesso de convergência ou insuficiência de divergência dos olhos e excessivo esforço acomodativo, levando a estrabismos convergentes e a pseudomiopias.

As miopias precoces já representam um sério problema de saúde pública em países desenvolvidos, especialmente em países asiáticos. Segundo a OMS, estima-se que, em 2050, metade da populaçáo global seja míope, dos quais $10 \%$ sejam altos míopes, situação que começa a ser denominada "epidemia de miopia" nos meios oftalmológicos, com potenciais impactos econômicos (Rosa, 2019).

Do mesmo modo, é o olhar da cultura oral, aprendido nas comunidades predominantemente marcadas pela oralidade, em espaços mais amplos, sendo, desde cedo, desenvolvido por meio de atitudes psicomotoras e visuais e mediante práticas que lhe são próprias. É o olhar dos ambientes mais amplos, mais distal, atento à periferia, menos convergente, desenvolvido nas crianças em açóes, como soltar pipa, jogar bola, no esconde-esconde etc.

Cada tipo de olhar se desenvolve ecologicamente em seu contexto cultural, inerente a cada estilo de vida, revelando uma diversidade visual própria aos diferentes indivíduos de uma sociedade, necessária à vida, e habilidades específicas para lidar com os diferentes ambientes e culturas.

É preciso ter em conta que o olhar da leitura e da escrita não é compartilhado por todos os alunos que ingressam na escola brasileira, requerendo o reconhecimento desse olhar ecológico e idiossincrático e a busca por práticas visuais inclusivas por todos 
os atores direta ou indiretamente envolvidos no processo de letramento, seja na família, na comunidade ou na escola.

A diversidade visual passa a ser a norma, e não mais a então considerada "normalidade" visual, e a escola deverá estar preparada para acolher os diferentes olhares de seus alunos, reconhecendo-os como habilidades culturalmente instituídas, e buscar promover a transição tanto no oral-letrado quanto no letrado-oral, vencendo todos os tipos de sensação de inadequação visual que por ventura possam existir, pois serão desenvolvidas habilidades binoculares necessárias não somente à escola, mas também à vida.

Em conclusão, considero fundamental a aproximação entre os profissionais das áreas da Ortóptica, das demais áreas das ciências da visão e da Educação Inclusiva, de modo a refletirem sobre essa complexa temática e juntos buscarem novas formas de se promover a necessária transição dos diversos olhares ecologicamente instituídos em direção ao olhar educado, discriminativo e disciplinado da cultura escrita.

\section{Referências}

BOURNE, R. R. A et al. Magnitude, temporal trends, and projections of the global prevalence of blindness and distance and near vision impairment: a systematic review and meta-analysis. The Lancet Global Health, v. 5, set. 2017. Disponível em: https://bit.ly/2xLCm4L. Acesso em: 07 jun. 2019.

BRASIL. Constituição da República Federativa do Brasil. Brasília: Senado Federal, Subsecretaria de Edições Técnicas, 2005.

. Ministério da Saúde. As Cartas de Promoção da Saúde. Disponível em: http://bvsms.saude.gov.br/bvs/publicacoes/cartas_promocao.pdf. Acesso em 08 jun. 2019.

. Lei n. ${ }^{\circ}$ 8.080/1990. Lei Orgânica da Saúde. Disponível em: http:// www.planalto.gov.br/ccivil_03/leis/L8080.htm. Acesso em: 04 nov. 2016.

. Portaria n. ${ }^{\circ}$ 957/2008. Política Nacional de Atenção em Oftalmologia. Disponível em: https://bit.ly/2X26TG8. Acesso em: 04 mar. 2011. 
. Lei n. ${ }^{\circ}$ 13146/2015. Lei brasileira de inclusão da pessoa com deficiência. Disponível em: http://www.planalto.gov.br/ccivil_03/_ato2015-2018/2015/ lei/l13146.htm. Acessado em: 20 ago. 2016.

. Ministério da Saúde: Portaria no 957/2008. Politica Nacional de Atençáo em Oftalmologia. Disponível em: https://bit.ly/2X26TG8. Acesso em: 04 mar. 2011.

BRICOT, Bernard. Posturologia. 2. a ed. Trad. Angela Bushatsky. Sáo Paulo: Ícone, 2001.

IAPB. Vision 2020. The right to sight. Disponível em: https://www.iapb.org/ vision-2020/who-facts/. Acesso em: 07 jun. 2019.

MENDES, I. A. C. "Desenvolvimento e saúde: a Declaração de Alma-Ata e movimentos posteriores". Rev. Latino-Americana de Enfermagem, v.12, n. 3, Ribeirão Preto, mai-jun., 2004. Disponível em: https://bit.ly/3dQuMqq. Acesso em: 08 jun. 2019.

OMS. Universal eye health: a global action plan 2014-2019, 2013. Disponível em: http://www.who.int/blindness/AP2014_19_English.pdf?ua=1. Acesso em: 05 nov. 2016.

ONU. Declaração mundial sobre a educação para todos. Jomtien, 1990. Disponível em: http://unesdoc.unesco.org/images/0008/000862/086291 por.pdf. Acesso em: 04 nov. 2016.

OPAS. Carta de Ottawa. 1986. Disponível em: http://www.opas.org.br/carta-de-ottawa/. Acesso em: 04 nov. 2016.

ROSA, J. "Qual é o impacto da 'epidemia de miopia' na produtividade global?”. Revista Universo Visual, 2019. Disponível em: https://bit.ly/3ax8N5A. Acesso em: 08 maio 2019.

SECIN, V. K. A. V. Construção do conceito social de intervençâo terapêutica ortóptica: o ortoptista como agente informal da Educação (dissertação). UERJ, 2005.

"A visão de mundo e sua representação: a propósito da trilogia 'clínica, cultura e fracasso escolar'. In SENNA, L. A. G. Letramento: principios e processos. Curitiba: IBPEX, 2007.

. Ortóptica, oralidade e o letramento: estudo descritivo e comparativo sobre a visão binocular dos indígenas Guarani Mbya da aldeia Sapukai (RJ) (tese). UERJ, 2011.

. A visäo binocular dos Guarani Mbya: ortóptica, oralidade e letramento. Curitiba: Appris, 2016.

et al. "Posturologia e o captor ocular: a importância do ortoptista na Equipe Interdisciplinar Postural”. Revista Saúde, Sexo e Educação-IBMR, ano XIII. n. 34/35, pp 53-59, 2004.

SENNA, L. A. G. (org.). Letramento: princípios e processos. Curitiba: IBPEX, 2007. 
168 O cotidiano escolar de crianças, jovens e adultos em roda de conversas "O conceito de letramento e a teoria da Gramática: uma vinculaçáo necessária para o diálogo entre as ciências da linguagem e a educação". Revista DELTA. São Paulo: PUC-SP, 2007, pp. 45-70. Disponível em: www.senna. pro.br. Acesso em: 03 mar. 2009.

SOUZA-DIAS, C. R. e GOLDCHMIT, M. Os estrabismos: teoria e casos comentados. Rio de Janeiro: Cultura Médica, 2011.

TALEB, A. et al. Prevenção à cegueira: dez anos para 2020. Conselho Brasileiro de Oftalmologia. Rio de Janeiro: Wallprint, 2010.

VON NOORDEN, G. K. e CAMPOS, E. C. Binocular vision and ocular motility: theory and management of strabismus. 6. Ed. Saint Louis - London Philadelphia - Sydney - Toronto: Mosby, Inc., 2002. 